\title{
Concentration of nitric oxide products in bronchoalveolar fluid obtained from infants who develop chronic lung disease of prematurity
}

\author{
Julian R Vyas, Andrew E Currie, David E G Shuker, David J Field, Sailesh Kotecha
}

\begin{abstract}
Aims-To determine if nitric oxide (NO) products (nitrate and nitrite) are increased in bronchoalveolar lavage (BAL) fluid obtained from infants who develop chronic lung disease of prematurity (CLD).

Methods-One hundred and thirty six serial bronchoalveolar lavages were performed on 37 ventilated infants (12 with CLD, 18 with respiratory distress syndrome (RDS), and seven control infants) who did not receive inhaled NO.

Results-During the first week of life nitrate concentration was between 25-31 $\mu \mathrm{mol} / 1$ in all three groups. Thereafter, the concentration of BAL fluid nitrate decreased to $14 \mu \mathrm{mol} / 1$ and $5.5 \mu \mathrm{mol} / 1$, respectively in the RDS and control groups by 14 days of age. In contrast, nitrate in the CLD infants remained constant until 28 days of age $(31.3 \mu \mathrm{mol} / 1$ at day $14 ; \mathrm{p}<0.05)$. In all BAL fluid samples the mean concentration of nitrite was $<1.2$ $\mu \mathrm{mol} / 1$ throughout the first 28 days with no significant differences noted among the three groups.

Conclusion-The similar concentration of BAL fluid nitrate in all groups during the first week of life suggest that NO may be important in the adaptation of the pulmonary circulation after birth. However, persistence of nitrate in the BAL fluid of infants with CLD during the second week may reflect pulmonary maladaptation, or, more likely, persisting pulmonary inflammation.
\end{abstract}

(Arch Dis Child Fetal Neonatal Ed 1999;81:F217-F220)

Keywords: chronic lung disease of prematurity; nitric oxide; nitrate; bronchopulmonary dysplasia

\footnotetext{
Department of Child

Health

Centre for

Mechanisms of Human

Toxicity

University of Leicester

Leicester LE2 7LX

J R Vyas

A E Currie

D J Field

S Kotecha

MRC Toxicology Unit University of Leicester D E G Shuker

Correspondence to: Dr Sailesh Kotecha.

Accepted 23 April 1999
}

Chronic lung disease of prematurity (CLD) is a common sequelae of respiratory distress syndrome (RDS) in preterm infants. ${ }^{12}$ Although the risk factors for CLD, which include oxygen toxicity, barotrauma, immaturity, infection, and patent ductus arteriosus, ${ }^{1-3}$ have been identified, the exact pathophysiology of CLD remains unknown. However, persisting pulmonary inflammation has been increasingly reported in association with the development of CLD. $^{4-9}$ Many of these pro-inflammatory cytokines, including tumour necrosis factor $\alpha$, interleukin-1, and interleukin-6, can increase the expression of inducible nitric oxide synthase (iNOS) in a variety of cell types. ${ }^{10} 11$
In 1987, Palmer et $a l^{12}$ and Ignarro et $a l^{13}$ reported that endothelial derived relaxing factor was nitric oxide (NO). It has since been shown that $\mathrm{NO}$ is a ubiquitous molecule with many diverse physiological functions, including relaxation of smooth muscle in blood vessels, ${ }^{14}$ neurotransmission, ${ }^{15}$ effects on immune function ${ }^{16-18}$ and platelet function. ${ }^{19} \mathrm{NO}$ production may be increased in diseases, such as asthma, ${ }^{2021}$ pneumonia, ${ }^{22}$ and sepsis. ${ }^{23} \mathrm{NO}$ may therefore have an important role in the pathophysiology of respiratory disease. The role of NO in the pathogenesis of CLD is currently unknown.

$\mathrm{NO}$ is formed by the enzyme nitric oxide synthase from L-arginine and it has a short half life of $<1$ second in blood. ${ }^{24}$ The oxidation reactions of NO are complex and involve nitrogen in many different oxidation states. NO combines extremely rapidly with superoxide radicals to produce peroxynitrite. This reaction occurs preferentially to that of superoxide inactivation by superoxide dismutase. ${ }^{25}$ Peroxynitrite is unstable at physiological $\mathrm{pH}$ and readily decomposes to form nitrite and nitrate. ${ }^{26}{ }^{27}$ Both these products may also be formed from nitrogen dioxide, low concentrations of which may be present if endogenous $\mathrm{NO}$ is produced in the inflammatory environment of infants who subsequently develop CLD.

As pulmonary inflammation is associated with the development of CLD, and because pro-inflammatory cytokines increase the expression of iNOS, we thought that infants who developed CLD would have increased production of endogenous NO. To assess the production of endogenous NO, we determined the concentration of nitrate and nitrite in bronchoalveolar lavage (BAL) fluid obtained from infants who did and did not develop CLD, but who had not received inhaled NO.

\section{Methods}

Newborn infants requiring mechanical ventilation were recruited to the study. Three groups of infants were studied: (a) those with CLD, comprising infants who were initially ventilated for RDS and who were oxygen dependent and had chest radiographic changes at 28 days of age $^{28}$; those with RDS, comprising infants who were ventilated for RDS, but who were nursed in air, and had a normal chest $x$-ray picture by 28 days of age; and controls who required ventilation for non-respiratory reasons and required an $\mathrm{FIO}_{2}$ of less than 0.28.

Infants who were diagnosed as having persistent pulmonary hypertension of the new- 
Table 1 Patient characteristics

\begin{tabular}{llll}
\hline & CLD & RDS & Control \\
\hline Number & 12 & 18 & 7 \\
Female:male & $5: 7$ & $8: 10$ & $1: 6$ \\
Birthweight (g) & $780(630-1070)$ & $1390(970-3480)$ & $2230(2180-2970)$ \\
Gestational age (weeks) & $26(23-28)$ & $29.5(27-39)$ & $35(31-39)$ \\
Antenatal dexamethasone & $11(92 \%)$ & $11(61 \%)$ & $1(14 \%)$ \\
$\quad \begin{array}{l}\text { Surfactant administration } \\
\text { Day 1 maximum peak inspiratory }\end{array}$ & $12(100 \%)$ & $18(100 \%)$ & $0(0 \%)$ \\
$\quad$ pressure (cm $\left.\mathrm{H}_{2} \mathrm{O}\right)$ & $18(14-36)$ & $19(13-22)$ & $16(15-20)$ \\
$\begin{array}{l}\text { Day 1 maximum FIO } \\
\text { Day 1 maximum mean airway }\end{array} \quad$ & $0.46(0.24-1.0)$ & $0.35(0.25-0.76)$ & $0.25(0.21-0.31)$ \\
$\quad$ pressure (cm $\left.\mathrm{H}_{2} \mathrm{O}\right)$ & $8.5(5-18)$ & $9(5-13)$ & $6(4-8)$ \\
Day 1 maximum oxygenation index & $6.4(2-21.3)$ & $7.9(1.2-14.2)$ & $2.4(2.2-3.6)$ \\
$\quad$
\end{tabular}

Median values (range) are shown. CLD = chronic lung disease of prematurity; RDS = respiratory distress syndrome. born by echocardiography or who had received inhaled nitric oxide treatment were excluded from the study. Infants of mothers who had infection or prolonged rupture of the membranes (of greater than 48 hours) were also excluded as were infants with infection at any time verified by positive blood or endotracheal secretion culture.

Informed consent was obtained from the parents and the study was approved by the local research ethics committee.

Bronchoalveolar lavage was performed twice weekly at the time of routine endotracheal tube suction until extubation or 28 days of age, as described before. ${ }^{29}$ The infant was placed supine with the head to the left. A 5 FG suction catheter was passed until resistance was felt. One $\mathrm{ml} / \mathrm{kg}$ of physiological saline was then instilled and aspirated immediately. This process was repeated and the 2 aliquots were pooled. The fluid was centrifuged within 10 minutes of collection at $500 \times g$ for 10 minutes and the supernatant fluid stored at $-70^{\circ} \mathrm{C}$ for subsequent analysis of nitrite and nitrate.

\section{ASSAY METHODS}

Nitrite assay

The samples were thawed on ice to prevent degradation of nitrite and were centrifuged in $12 \mathrm{kDa}$ molecular weight cutoff ultrafiltration microcentrifuge tubes (Whatman, Maidstone) at $12000 \mathrm{rpm}$ for 35 minutes to remove proteins which may interfere with the assay. Nitrite concentration was determined using a commercial kit (Nitrate/Nitrite Fluorometric Assay Kit, Cayman Chemicals, Ann Arbor, USA) based on a fluorometric method described by Misko. ${ }^{30}$ Nitrite reacted with 2,3-diaminonaphthalene (DAN) to produce a fluorescent compound (excitation $365 \mathrm{~nm}$ and emission $450 \mathrm{~nm}$ ). The limit of detection for this assay was $0.2 \mu \mathrm{M}$ nitrite.

\section{Nitrate assay}

Nitrate was measured according to the manufacturer's instructions (Nitrate/Nitrite Fluorometric Assay Kit, Cayman Chemicals, Ann Arbor, USA). Briefly, nitrate was reduced to nitrite by an Aspergillus species nitrate reductase (E.C.1.6.6.2) in the presence of essential cofactors NADPH and flavine adenine dinucleotide (FAD). ${ }^{31}$ Nitrite was subsequently assayed as described above. The limit of detection was also $0.2 \mu \mathrm{M}$.
The median (range) is shown for gestation and birthweight of the infants studied. Because of skewed data, the means (SEM) of the log transformed data for nitrite and nitrate concentrations were calculated for which the anti-logs are illustrated. Multiple groups were compared using the non-parametric Kruskal-Wallis test and comparisons between groups were made using the Mann-Whitney $\mathrm{U}$ test. A $\mathrm{p}$ value of $<0.05$ was considered significant.

\section{Results}

Patient characteristics are shown in table 1 . One hundred and thirty six lavages were performed on 37 infants receiving mechanical respiratory support. Twelve infants (5 girls, 7 boys) developed CLD, 18 had acute RDS (8 girls, 10 boys) and seven infants ( 1 girl, 6 boys) were ventilated for non-respiratory reasons (4 for abdominal surgery, 1 for tracheooesophageal fistula with oesophageal atresia, 1 for mild asphyxia at birth and 1 for apnoea). Antenatal dexamethasone had been given to 11 of 12 mothers in the CLD group, 11 out of 18 in the RDS group, and one of seven in the control group. The birthweight and gestational age of the CLD group was significantly lower than that of the RDS or control groups (birthweight: CLD vs RDS $\mathrm{p}<0.05$, CLD vs controls $\mathrm{p}<0.05$; gestational age: CLD vs RDS $\mathrm{p}<0.05$, CLD vs controls $\mathrm{p}<0.05)$.

Surfactant (Survanta, Abbott Laboratories) was given to all the infants in both the CLD and RDS groups but none was given to infants in the control group. The first bronchoalveolar lavage was performed before the first dose of surfactant was administered. There were no differences between the CLD and RDS groups for maximum peak inspiratory pressure, maximum $\mathrm{FIO}_{2}$, mean airway pressure or oxygenation index on day 1 (table 1). As expected, the control group had a significantly lower maximum $\mathrm{FIO}_{2}$ and mean airway pressure $(\mathrm{p}<0.05)$ than the other two groups.

Nitrate concentration in BAL fluid for all three groups during the first week of life was between 25 and $30 \mu \mathrm{mol} / 1$ with little differences seen between the groups (fig 1). By 14 days of age, the concentration of nitrate in lavage fluid had decreased in the RDS and control groups to $14.2 \mu \mathrm{mol} / 1$ and $5.5 \mu \mathrm{mol} / 1$, respectively. In contrast, it remained at around the same level

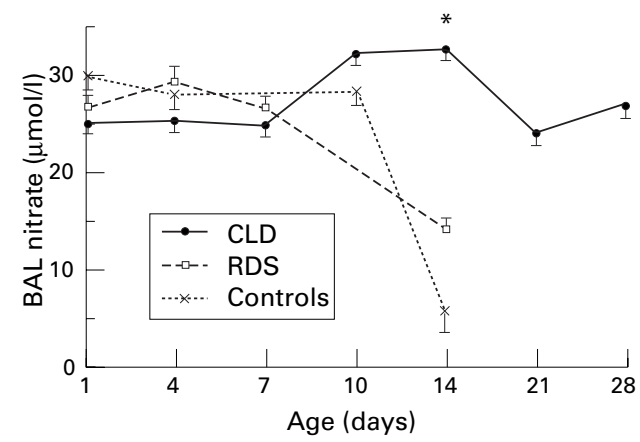

Figure 1 Mean (SEM) nitrate concentration in BAL fluid of infants who developed CLD, infants with RDS nursed in air by day 28, and infants ventilated for non-respiratory reasons (controls); ${ }^{\star} p<0.05$ CLD vs RDS vs controls. 


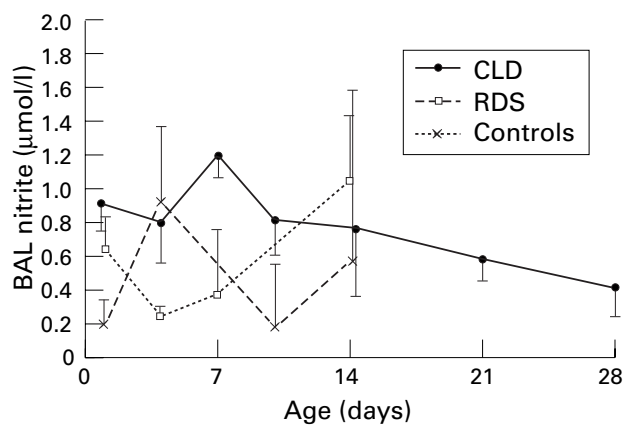

Figure 2 Mean (SEM) nitrite concentration in BAL fluid of infants who developed CLD, infants with RDS nursed in air by day 28, and controls.

in the CLD group until 28 days of age (31.3 $\mu \mathrm{mol} / 1$ at day $14, \mathrm{p}<0.05$ compared with the RDS and control groups. The mean concentration of nitrite in BAL fluid obtained from all three groups throughout the study period was less than $1.2 \mu \mathrm{mol} / 1$ with no differences noted between the groups (fig 2 ).

\section{Discussion}

The results have shown that nitrate concentration in BAL fluid from all three groups was very similar during the first week of life. During the second week of life, nitrate concentration remained high in the infants who progressed to CLD. In contrast, it decreased in the RDS and control groups. Nitrite concentration in BAL fluid was less discriminatory between the three groups, being less than $1.2 \mu \mathrm{mol} / 1$ throughout the study period.

The similar concentration of nitrate in all three groups during the first week of life suggests that there is a common cause for its production, independent of gestational age. In animal models NO is thought to have a role in transition of the fetal circulation to the adult circulation. ${ }^{32} 33$ Abman et al have shown that inhibition of NO synthase by the L-arginine analogue nitro-L-arginine in newborn lambs prevents the normal physiological decrease in pulmonary arterial resistance, suggesting that NO may have a role in the transition from fetal to adult circulation. ${ }^{32}$ It is tempting to speculate that the nitrate we detected reflects such a circulatory adaptation after birth in all groups. Further studies will be needed to determine if this is indeed the case.

There is evidence that the sensitivity of newborn piglet pulmonary arterial smooth muscle cells to NO increases after day 3 of life; therefore a lower concentration of $\mathrm{NO}$ is required for equivalent vasodilatory effect in the pulmonary circulation. ${ }^{33}$ This observation may explain the decrease in BAL fluid nitrate that we have seen during the second week of life in the RDS and control infants. The persistence of BAL fluid nitrate in the CLD group after the first week may be due to the change in sensitivity of the smooth muscle cells to NO not occurring. This may result in maladaptation of the fetal circulation in this group of babies.

Alternatively, the increase in BAL fluid nitrate in the CLD infants during the second week of life may be due to increased pulmonary inflammation. ${ }^{34}$ Pulmonary inflammation is increased in the lungs of babies who progress to CLD compared with those babies who recover from RDS. ${ }^{4-9}$ Certain pro-inflammatory cytokines found in BAL fluid in CLD, and which promote lung inflammation, will probably induce the expression of the inducible form NO synthase (iNOS), as has been shown in asthma ${ }^{35}$ and sepsis. ${ }^{36}$ The increase in nitrate in the CLD group during the second week of life may be due to inflammation in the lungs of babies who develop CLD. Further evidence for lung inflammation contributing to the production of $\mathrm{NO}$ is provided by animal models. Hyperoxia, which newborn preterm infants who progress to CLD are exposed to, can increase the production of nitrate and nitrite in the lungs of animals. ${ }^{37}$ In Arkovitz's model, inhibition of NO synthase (NOS) by L-NGnitro-L-arginine methyl ester (L-NAME) worsened hyperoxic acute pulmonary injury, suggesting that $\mathrm{NO}$ may protect the lungs from such injury. However, the mechanism of increased nitrate and nitrite production in BAL fluid with hyperoxia is unclear as iNOS expression was not increased. It may be that there is a balance of beneficial against adverse effects of NO depending on other prevailing factors.

In the inflammatory environment of the lung of infants who develop CLD, endogenously produced NO, as shown by our study, is likely to react with reactive oxygen species to form pro-oxidant products such as peroxynitrite. Peroxynitrite is an unstable product which rapidly nitrates tyrosine residues to form nitrotyrosine. ${ }^{38}$ Nitrotyrosine has been used as a marker of the presence of peroxynitrite in many inflammatory disorders, including rheumatoid arthritis. ${ }^{39}$ adult $\mathrm{RDS}^{40}$ and atherosclerosis. ${ }^{41}$ Further preliminary studies by our group have shown that infants who develop CLD (and who are not treated with inhaled NO) have increased nitrotyrosine in proteins obtained from BAL fluid (data not shown). This finding has been confirmed by others. ${ }^{42}$ More importantly, the formation of nitrotyrosine may interfere with phosphorylation of tyrosine residues in critical cell signalling pathways which result in cell proliferation and differentiation. ${ }^{43}$

We were unable to show any differences between the groups for BAL fluid nitrite. This is likely to have been due to either the instability of nitrite which is readily converted to nitrate in the oxygen enriched environment of the infant receiving oxygen treatment or due to oxidation to nitrate in storage even at $-70^{\circ} \mathrm{C}$. Other commonly encountered problems with studies such as ours include regular extubation of study infants as their clinical condition improves, the lack of a satisfactory marker for dilution of epithelial lining fluid, ${ }^{44}$ and difficulty of obtaining "normal" data for preterm infants.

In conclusion, our data show that, during the first week of life, nitrate in BAL fluid from ventilated infants was similar in all three groups studied. This suggests that NO may have a role in the transition of the fetal circulation to the postnatal circulation. Pulmonary NO production seems to persist in infants who develop 
CLD, possibly reflecting maladaptation of the pulmonary circulation in these infants, or ongoing pulmonary inflammation.

Dr Vyas was supported by the British Lung Foundation and Dr Andrew Currie by Action Research.

We thank the parents and nursing staff on the neonatal unit at the Leicester Royal Infirmary.

Data from this work formed part of an oral presentation at the 1998 American Thoracic Society, annual meeting, Chicago,

USA.

1 Currie AE, Kotecha S. Chronic lung disease of prematurity. Crit Care Med 1997;12:14-17.

2 Kotecha S, Silverman M. Chronic respiratory complications of neonatal disorders. In: Landau LI, Taussig LM, eds.
Textbook of Pediatric Respiratory Medicine. St Louis: C V Moxtbook of Pediatric R.

3 deLemos RA, Coalson JJ. The contribution of experimental models to our understanding of the pathogenesis and models to our understanding of the pathogenesis and treatment of bro

4 Kotecha S, Chan B, Azam N. Increase in interleukin-8 and soluble intercellular adhesion molecule-1 in bronchoalveolar lavage fluid from preterm infants who develop chronic lung disease. Arch Dis Child Fetal Neonatal Ed 1995;72:F90-F6

5 Kotecha S, Wangoo A, Silverman M, Shaw RJ. Increase in transforming growth factor- $\beta_{1}$ concentration in bronchoalveolar lavage fluid from infants with chronic lung disease of prematurity. F Pediatr 1996;128:464-9.

6 Kotecha S, Wilson N, Wangoo A, Silverman M, Shaw RJ. Increase in interleukin- $1 \beta$ and interleukin- 6 in bronchoalveolar lavage fluid from infants with chronic lung disease of prematurity. Pediatr Res 1996;40:250-6.

7 Watterburg KL, Carmichael DF, Gerdes JS, Werner S, Backstrom C, Murphy S. Secretory leukocyte protease inhibitor and lung inflammation in developing bronchopinhibitor and lung inflammation in developing

8 Jackson JC, Chi EY, Wilson CB, Truog WE, Teh EC, Hodson WA. Sequence of inflammatory cell migration into lung during recovery from hyaline membrane disease in premature newborn monkeys. Am Rev Respir Dis 1987;135:937-40.

9 Ogden BE, Murphy SA, Saunders GC, Pathak D, Johnson JD. Neonatal lung neutrophils and elastase/protease imbalance. Am Rev Respir Dis 1984:817-21.

10 Nathan C. Nitric oxide as a secretory product of mammalian cells. FASEB 7 1992;6:3051-64

11 Lincoln J, Hoyle CHV, Burnstock G. Nitric oxide in health and disease. Biomedical research topics series: 1. Cambridge: Cambridge University Press. 1997.

12 Palmer RMJ, Ferrige AG, Moncada S. Nitric oxide release accounts for the biological activity of endothelium-derived relaxing factor. Nature 1987;327:524-6

13 Ignarro LJ, Buga GM, Wood KS, Byrne RE, Chaudhuri G Endothelium derived relaxing factor produced and Endothelium derived relaxing factor produced and released from artery and vein $1987 ; 84: 9265-9$.

14 Moncada S, Higgs A. Mechanisms of disease; the L-arginine nitric oxide pathway. $N$ Engl f Med 1993;329:2002-12.

15 Snyder SH. Nitric oxide: first in a new class of neurotransmitters? Science 1992;257:494-6.

16 Kinsella JP, Parker TA, Galan H, Sheridan BC, Halbower AC, Abman SH. Effects of inhaled nitric oxide on pulmonary edema and lung neutrophil accumulation in severe experimental hyaline membrane disease. Pediatr Res 1997;41:457-63.

17 Iha $S$, Orita $K$, Kanno $T$, Utsume $T$, Sato $E F$, Inoue $M$, Utsumi K. Oxygen dependent inhibition of neutrophil respiratory burst by nitric oxide. Free Rad Res 1996;25:48998.

18 Niu X-F, Ibbotson G, Kubes P. A balance between nitric oxide and oxidants regulates mast cell-dependent
neutrophil-endothelial cell interactions. Circ Res 1996;79:992-9.

19 Radomski MW, Palmer RMJ, Moncada S. Endogenous nitric oxide inhibits human platelet adhesion to vascular endothelium. Lancet 1987;ii:1047-8.
20 Kharitonov SA, Yates D, Robbins RA, Logan-Sinclair R, Shinebourne EA, Barnes PJ. Increased nitric oxide in Shinebourne EA, Barnes PJ. Increased nitric oxide in
exhaled air of asthmatic patients. Lancet 1994;343:133-5.

21 Nelson BV, Sears S, Woods J, Ling CY, Hunt J, Clapper LM, Gaston B. Expired nitric oxide as a marker for childhood asthma. $\mathcal{F}$ Pediatr 1997;130:423-7.

22 Grasemann H, Ioannidis I, deGroot H, Ratjen F. Metabolites of nitric oxide in the lower respiratory tract of children. Eur F Pediatr 1997;156:575-8.

23 Wong HR, Carcillo JA, Burckart G, Kaplan SS. Nitric oxide production in critically ill patients. Arch Dis Child production in

24 Borland C. Endothelium in control. Br Heart $f$ 1991;66:405.

25 Gaston B, Drazen JM, Loscalzo J, Stammler JS. The biology of nitrogen oxides in the airways. Am $\mathcal{F}$ Respir Crit Care Med 1994;149:538-51.

26 Stamler JS, Singel DJ, Loscalzo J. Biochemistry of nitric oxide and its redox-activated forms. Science 1992;258:1898-902.

27 Gaston B, Drazen JM, Loscalzo J, Stamler JS. The biology of nitrogen oxides in the airways. Am $\mathcal{F}$ Respir Crit Care Med 1994;194:538-51.

28 Bancalari E, Abdenour GE, Feller R, Gannon J. Bronchopulmonary dysplasia: clinical presentation. $\mathcal{F}$ Pediatr 1979;95:819-23.

29 Grigg J, Arnon S, Silverman M. Fractional processing of sequential bronchoalveolar lavage fluid from intubated babies. Eur Respir F 1992;5:727-32.

30 Misko TP, Schilling RJ, Salvemini D, Moore WM, Currie MG. A fluorometric assay for the measurement of nitrite in biological samples. Anal Biochem 1993;214:11-16.

31 Schmidt HHHW, Kelm M. Determination of nitrite and nitrate by the Griess reaction. In: Feelisch M, Stamler JS, eds. Methods in nitric oxide research. Chichester: John Wiley,

32 Abman SH, Chatfield BA, Hall SL, McMurty IF. Role of endothelium-derived relaxing factor during transition of pulmonary circulation at birth. Am f Physiol 1990;259:H1921-H7.

33 Zellers TM, Vanhoutte PM. Endothelium-derived relaxations of piglet pulmonary arteries augment with maturation. Pediatr Res 1991;30:176-80.

34 Barnes PJ, Liew FY. Nitric oxide and asthmatic inflammation. Immunol Today 1995;16:128-30.

35 Barnes PJ. NO or no NO in asthma. Thorax 1996;51:21820

36 Carraway MS, Piantadosi CA, Jenkinson CP, Huang Y-C T. Differential expression of arginase and iNOS in the lung in sepsis. Exp Lung Res 1998;24:253-68.

37 Arkovitz MS, Szabo C, Garcia VF, Wong HR, Wispe JR. Differential effects of hyperoxia on the inducible and constitutive isoforms of nitric oxide synthase in the lung. Shock 1997;7:345-50.

38 Beckman JS, Koppenol WH. Nitric oxide, superoxide and peroxynitrite: the good, the bad and the ugly Am $\mathcal{F}$ Physiol

39 Kaur H, Halliwell B. Evidence for nitric oxide-mediated oxidative damage in chronic inflammation. FEBS Lett 1994;350:9-12.

40 Haddad IY, Pataki G, Hu P, Galliani C, Beckman JS, Matalon S. Quantitation of nitrotyrosine levels in lung sections of patients and animals with acute lung injury. $\mathcal{F}$ Clin Invest 1994;94:2407-13.

41 Moriel P, Abdulla DS. Nitrotyrosine bound to beta-VLDL apoprotein: a biomarker of peroxynitrite formation in experimental atherosclerosis. Biochem Biophys Res Comтип 1997;32:332-5.

42 Hallman M, Bry K, Turbow R, Waffarn F, Lappalainen U. Pulmonary toxicity associated with nitric oxide in term infants with severe respiratory failure. $f$ Pediatr 1998;132:827-9.

43 Yu S-M, Hung L-M, Lin C-C. cGMP-elevating agents suppress proliferation of vascular smooth muscle cells by inhibiting the activation of epidermal growth factor signalling pathway. Circulation 1997;95:1269-77.

44 Kotecha S, Grigg J, Reinout RJ. ERS Task Force On Bronchoalveolar Lavage In Children: Special Consideration in Neonates. Eur Respir $\mathcal{F}$ (in press). 